\title{
Energy Efficiency in Residential Buildings with Well-Established Energy Management Systems
}

\author{
Rolf Katzenbach, Frithjof Clauss, and Jie Zheng
}

\begin{abstract}
A rational exploitation and efficient utilization of energy over a wide field of production and life is the main direction and object of modern society development, in order to keep its sustainability for nowadays and future. With the rapidly economic growth and strong competition among all the countries worldwide, the excessive thirst for energy has become more serious than ever before. Therefore, a series of efforts had to be made to keep the stability and sustainability of the global energy market. To achieve a Green and growth path, German government has made the decision to direct its energy supply towards sustainable energy, particularly renewable energy resource, and has also developed a comprehensive and effective energy concept on the basis of scientific studies. Not only in trade and industry as well transport sector, more energy saving or efficient use has been emphasized and optimized in domestic fields which are interested by everyone's daily life because it is supposed to be exploited enormous energy and resource saving potential. It is repeatedly stressed that energy efficiency is the most cost-effective pillar supporting Germany's energy turnaround which is achieved not only depending on continuous technical innovation and research, more important on a complete set of energy management systems and a healthy economic mechanism of energy policies.

Depending on the authors' theoretical research and practical work on the relevant area, this paper is to present the advanced experience of energy efficiency with its existing sophisticated energy management systems in Germany, especially how energy efficiency has been enhanced in residential fields and which can be made more widespread as well what shall be moved forward further. Comprehensive information exchange and potential coordination are proposed to go further in the field of energy efficiency for a smart, sustainable and clean growth.
\end{abstract}

Index Terms - Climate and energy package, energy efficiency and systematized resource management, renewable energy, smart metering.

\section{INTRODUCTION}

The Climate and Energy Package 20-20-20 were set by European Union in March 2007 and entered into force in June 2009, which set three key objectives for 2020 [1]:

- $20 \%$ reduction in EU greenhouse gas emissions on 1990 levels (actually EU is on track to a $30 \%$ reduction in

Manuscript received August 10, 2014; revised June 12, 2015.

Rolf Katzenbach is with the Institute and the Laboratory of Geotechnics and TU Darmstadt Energy Center, Technische Universität Darmstadt, 64287 Darmstadt, Germany (e-mail: katzenbach@geotechnik.tu-darmstadt.de)

Frithjof Clauss is with the TU Darmstadt Energy Center, Technische Universität Darmstadt, 64287 Darmstadt, Germany (e-mail: clauss@energycenter.tu-darmstadt.de).

Jie Zheng is with the Excellence Graduate School of Energy Science and Engineering, Technische Universität Darmstadt, 64287 Darmstadt, Germany (tel.: 0049-6151-75740; e-mail: zheng@energycenter.tu-darmstadt.de).
2030);

- $20 \%$ increase of the share of EU energy consumption produced from renewable resources, including $10 \%$ vehicle biofuels on 1990 levels;

- $20 \%$ improvement in the EU's energy efficiency on 1990 levels by reducing primary energy use.

In addition, a long term climate and energy target aims to achieve an $80-95 \%$ greenhouse gas emission reduction in 2050. These targets try to meet its ambitious climate and energy targets for the future decades, in other words to transform Europe itself into a highly energy efficient, low carbon economy over the next decade. With a higher demand on itself Germany has raised its goals with a $40 \%$ reduction of $\mathrm{CO}_{2}$ emissions against the level in 1990 until 2020, at least $30 \%$ renewable energy in electricity generation and a $14 \%$ share in heat supply can be provided by renewable energy by 2020 , as well its energy productivity will be doubled by 2020 compared with 1990

The climate change and the increasingly obvious energy famine have become some of biggest challenges. In Germany the final energy consumption for building (residential, commerce and service sectors) is accounted as the largest proportion $44 \%$ (actually the final energy consumption in the residential and commercial sectors was $1,2 \%$ lower in 2000 than in 1990.), the rest shares are contributed to industry $27 \%$ and $29 \%$ by traffic and transport. However, same like other countries the most proportion of $\mathrm{CO}_{2}$ emission in Germany still fell on the energy industry sector, followed by traffic and transport, manufacturing industry, household sector and others, shown in Fig. 1.

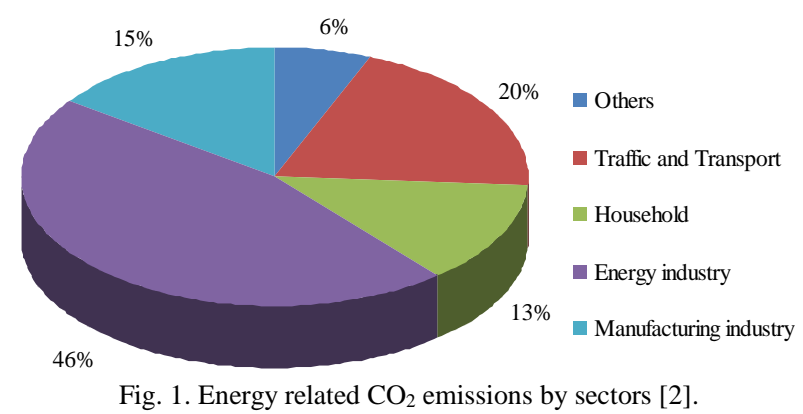

Therefore a continuous study and investment has been and still is focused on the energy efficiency in residential sector in all its relevant aspects, which aims to discover its maximal energy saving potential.

\section{ENERGETIC INVOLVEMENT IN RESIDENTIAL INDUSTRY}

According to the statistics in Federal Statistical Office until May 31, 2013 there were around 80,2 Mio. inhabitants in 
Germany and ca. 41,3 Mio. households or apartments (house). Energy consumption and therefore $\mathrm{CO}_{2}$ emissions in residential sector (esp. private household) became a serious matter of concerns of energy supply. Enhancing energy efficiency and optimizing resource management and allocation will take up one of the most important tasks to achieve a domestic sustainability.

Final energy consumption in residential sector is generally divided into different utilization for each household.

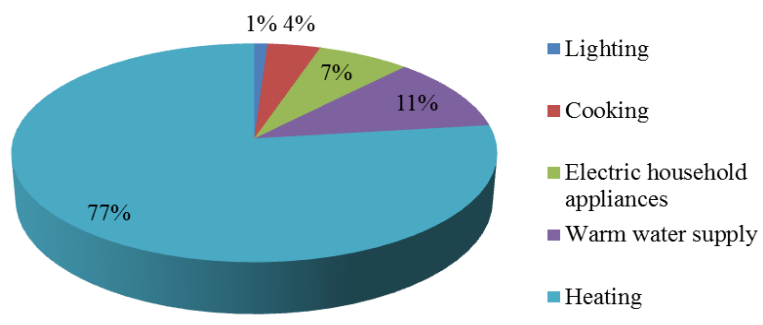

Fig. 2. Common final energy consumption in German household.

The data shown on the Fig. 2 about final energy consumption in residential sector illustrate that approx. $77 \%$ final energy supply in residential building is consumed for heating, behind followed by an $11 \%$ share for warm water provision and the rest $12 \%$ is divided to lighting $1 \%$, cooking $4 \%$ and other electric application $7 \%$. How to manage the energy consumption especially in the part of heating and warm water supply with a complete and effective system with a view to each involved aspect is the focus of research and practical investments, which is proposed to enhance the energy efficiency and reduce energy consumption without lowering the quality of daily life. A successful energy and resource management consists of not only the optimized building techniques as objective factor, but more important the subjective or initiative factors and any energy saving possibilities by energy users.

\section{TECHNICAL IMPROVEMENT FOR ENERGY CONSERVATION}

In connection with energy saving in residential buildings by the way of technical optimization it shall be distinguish the building types between new construction and existing (housing) building. Germany government encourages the demand of retrofits for old or existing buildings, at the same time it also seeks to tighten building standards for new buildings and to control rising electricity use for appliances, electronics, lighting and other devices [3].

The Energy Conservation Act (German: "Energieeinsparungsgesetz", short EnEG) and with regard to it the Energy Regulation (German: "Energieeinsparungsverorderung", short $E n E V$ ) were passed to meet the EU requirements and regulate its own energy efficiency policy for residential buildings in Germany. A series of concrete requirements for new and existing buildings has been defined in these acts.

\section{A. Technical Improvement Measures for Energy Saving in New Construction}

In Germany a proved primary energy balance in the entire year is the basic requirement for new (residential) construction. According to EnEV 2007 the annual primary energy demand is limited depending on the specific heat transmission losses in comparison on the heat transferring outer skin of the building [4]. Insofar as it can be ascertained, there are two energy saving concepts developed for the new housing construction. Since the beginning of the 1990s Passive House has been developed in Germany. As an effective energy-saving building standard Passive House has been developed and popularized which can achieve energy and economy efficiency, improve living comfort and environmental friendliness at the same time. Fig. 3 illustrates the design concept and application principles of passive house.

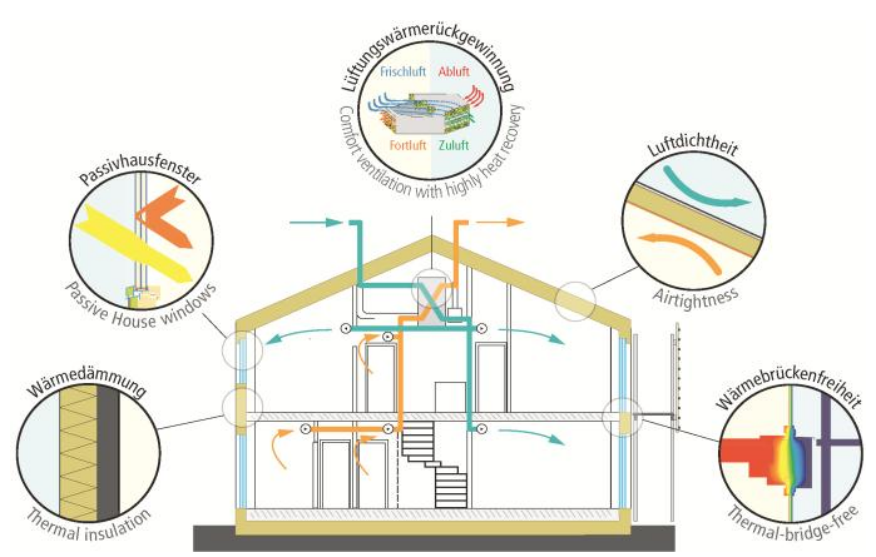

Fig. 3. Basic principles apply for the construction of passive houses [5].

Passive House Planning Package (PHPP) formulates a set of provisions by planning, optimizing and verifying each newly constructed Passive House. From a different perspective all the design and implementation aspects are taken into full consideration, in order to meet the basic Passive House principles: super insulation, windows with particularly high thermal insulation value, stringent levels of airtightness, air-to-air heat exchanger, minimal thermal bridging and total primary energy use (including DHW, heating, cooling, auxiliary and household electricity) shall be less than $120 \mathrm{kWh} / \mathrm{m}^{2} /$ year. Passive House or zero-energy buildings are designed as new building construction for the market.

Another energy saving improvement suggestion for new construction is the utilization of renewable energy, such as solar panel on roof, geothermal energy. According to the German Renewable Energy Heat Act (German: Erneuerbare-Energien-Wärmegesetz, short EEWärmeG) it is prescribed that by using solar panel at least $15 \%$ heating and cooling energy demand shall be provided by solar energy, at least $30 \%$ by using gaseous biomass and $50 \%$ by liquid biomass energy demand can be fed for heating and cooling. The renewable energies in heating for new construction are proposed to supply $14 \%$ energy demand in 2020.

\section{B. Technical Improvement Measures for Energy Saving in Existing (Housing) Building}

The limit value of final energy and primary energy consumption is suggested to be reduced $30 \%$. Complete or part energetic refurbishment in existing (housing) building involves on the one hand the building construction itself, on the other hand all the interior energy facilities, which covers 
mainly the heating, hot water, ventilation and air-condition. Maintenance of energy systems is referred to:

- Retrofitting of building construction in internal \& external thermal insulation like walls, windows, façade and basement:

- Improvement of heating system through regulating the heating curve or checking the missing insulation with specific low-cost interventions like smart metering system;

- Replacement of the whole ventilation system and heating system;

- Application of low energy building equipment.

Currently there are no concrete requirements or provisions for renewable energy in existing buildings or refurbishments [4].

\section{SYSTEMATIC ENERGY MANAGEMENT BY EACH STAKEHOLDER}

Except the necessary technical innovation in housing building, energy management system could never be complete and well-established without concerning all the other aspects including economic, political, social even educational influence factors. Instead of a central management concept it prefers to a decentralized management system which clarifies the performance of each stakeholder for optimizing the energy efficiency.

\section{A. Stakeholder - Tenants}

As the direct beneficiaries of building refurbishment or any other energy efficiency measures the tenants conversely impact energy and resource conservation and environment protection through their energy using activities. Based on some investigation of energy consumption in social housing buildings in Germany, increasing energy and resource using awareness by users or tenants has a very practical significance. Because of some conventional living habits or other traditions people spend actually too much more energy in their daily life unconsciously than they really need. A multi-level and multi-form training and education service has been proved as an effective way to convey more energy saving information to tenants of all ages those have different educational, occupational and income levels. A proposed also proved work process by authors with involved practical projects aiming to enhance the energy conservation consciousness in tenants group is illustrated in Fig. 4 below:

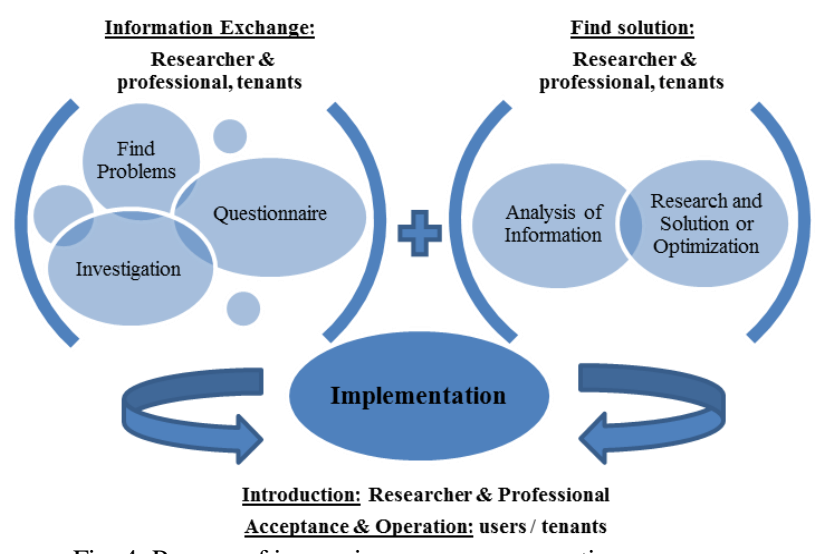

Fig. 4. Process of improving energy consumption awareness.

\section{B. Stakeholder - Building Owners}

Building owners and energy providers are on one hand in charge of an effective and convenient energy supply for their customers (users, namely tenants), on the other hand they have to be responsible for energy efficiency and the contribution of climate and environmental protection during the whole processes of their business, with these precondition and requirements to try to reduce the operation costs and achieve the maximum profits.

Resource Consumption Management Service utilized by building owners site plays a leading role of our research and project development. It refers to energy and water management application to avoid the peak consumption, to manage the production and distribution of renewable energy and to optimize the domestic energy consumption in line with supplier requirements and tariffs.

In addition, in Germany different policies (EEG, EnEV, EnEG etc.), regulations, standards and financial support or special bank group (kfW Bankengruppe) directed towards energy saving and renewable energy as well energy education are carried out to achieve a green, efficient and sustainable life and work area for all the stakeholders. New promotional programs or incitements motivated and supported by policy makers are supposed to introduce people to merge into an energy saving and sustainable society with a proper and positive way. It can be a very strong driver to change the inefficient energy using behavior. In Germany the public policies aim to refurbish the entire housing stock and all public buildings by 2030 .

\section{SUMMARY}

It is obvious that the EU Climate and Energy Package not only has set a series of binding EU-wide targets for greenhouse gas emission reduction, renewable energy promotion and energy efficiency improvements but also proposed to prescribe to a larger extent how targets are shared across countries and segments of the EU economy [6]. Germany plays a leadership role in energy efficiency and has so far influenced the international climate protection process to a decisive extend. Especially for the residential sector the Federal Environment Agency Germany has planned to reduce emissions by private households at a level of 39 Mio. tonnes of $\mathrm{CO}_{2}$ and $10 \mathrm{Mio}$. tonnes of $\mathrm{CO}_{2}$ in the commercial, trade and services sector [7].

The energy efficiency is an ongoing effort and have to be increased, however it is directly or indirectly combined with economic, political and almost all the other social areas. As long as an investment into energy efficiency is effective and profitable for all the stakeholders or beneficiaries, it will be optimized continuously and succeed, any constructive contribution and mutual supports cross a wide domains are indispensable from beginning to end.

\section{REFERENCES}

[1] The 2020 climate and energy package. [Online]. Available: http://ec.europa.eu/clima/policies/package/index_en.htm

[2] Energie in deutschland — Trends und hintergründe zur energieversorgung, Bundesministerium für Wirtschaft und Technologie (BMWi), Berlin, Germany, p. 50, February 2013. 
[3] A. Hermann, D. Jeff, A. Hobbs, A. Novikava, Y. Xiu, and S. Y. Zhang, "Buildings energy efficiency in China, Germany, and the United States," Climate Policy Initiative CPI Report, p. iii, April 2013.

[4] A. Krüger: "EU and German Requirements on Energy Efficiency of Residential Buildings," presented at the Miami Conference, 2009.

[5] Passive house requirements. [Online]. Available: http://www.passiv.de/en/passive-house-requirements.htm

[6] C. Böhringer and A. Keller, "Energy security: An impact assessment of the EU climate and energy package," Department of Economics, University of Oldenburg, Germany, 2011.

[7] C. Erdmenger, H. Heramnn, J. Tambke, M. Bade, and R. Beckers. Climate protection in Germany: $40 \%$ reduction of $\mathrm{CO}_{2}$ emissions by 2020 compared to 1990. Umweltbundesamt für Mensch und Umwelt. [Online]. Available: http://www.umweltbundesamt.de

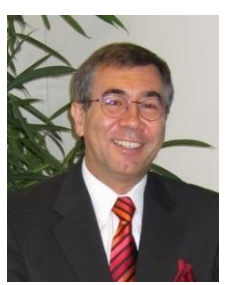

Rolf Katzenbach was born in Frankfurt am Main, Germany, on May 13, 1950. He studied at Technische Universität Darmstadt (TUD), Germany, Faculty of Civil Engineering.

His was a scientific assistant at the Institute for Soil Mechanics and Foundation Engineering at TUD Since 1993, he was a university professor at TUD and the head as well as the director of the Institute and Laboratory of Geotechnics of Technische Universität Darmstadt, also as a senior-partner and co-owner of Ingenieursozietät.

Professor Katzenbach was the chairman of the International Technical Committee TC 5, Environmental Geotechnics of the International Society for Soil Mechanics and Geotechnical Engineering (ISSMGE) from 1998 to 2002, since 2000 he was the chairman of CEN Committee 341 Geotechnical Investigation and Testing of European Committee of Standardization, since 2002 he was the chairman of the International Technical Committee TC 18 Deep Foundations of the International Society for Soil Mechanics and Geotechnical Engineering (ISSMGE), since 2004 he was the vice president of the European Expert Group ELGIP (European Large Geotechnical Institutes Platform) and the chairman of Society of Sworn Experts in Germany, and since 2006 he was the president of the European Expert Group
ELGIP (European Large Geotechnical Institutes Platform) as well as the chairman of Society of Engineers for Geothermics.

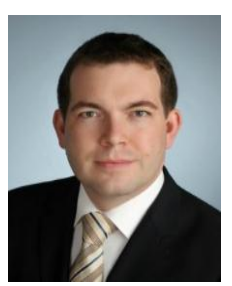

Frithjof Clauss was born in Frankfurt am Main Germany, on April 3, 1975. He graduated from Technische Universität Darmstadt (TUD), Germany, Faculty of Civil Engineering, and studied at Technische Universität Darmstadt and University of California, Berkeley.

His employment experience includes scientific research at the Institute and Laboratory of Geotechnics at Technical University Darmstadt. Since 2008 he has been the executive director of TU Darmstadt Energy Center. His work activity focuses on geothermal engineering, renewable energies and energy efficiency, strategic planning.

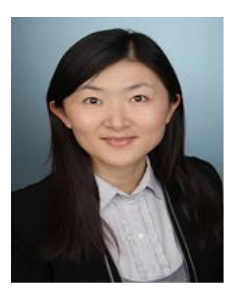

Jie Zheng was born in Guizhou Province, China, on August 30, 1980. She graduated from Tongji University, China, with her bachelor degree and received a diploma degree from the Faculty of Civil Engineering Technische Universität Darmstadt (TUD), Germany.

Her employment includes work experience as a civil engineer in China Railway First Survey and Design Institute Group Ltd. Since 2012 she worked as a scientific research assistant at Technische Universität Darmstadt, and since 2014 as a Ph.D. candidate at TU Darmstadt, Graduate School of Excellence Energy Science and Engineering. Her work and research activity focuses on geothermal energy, renewable energies, energy efficiency and user behavior analysis in residential building sector. 